\title{
Article \\ Short-Term Effect of Wearing of Extended Depth-of-Focus Contact Lenses in Myopic Children: A Pilot Study
}

\author{
Gema Corpus ${ }^{1}$ and David P. Piñero ${ }^{1,2, *(D)}$ \\ 1 Department of Optics, Pharmacology and Anatomy, University of Alicante, 03690 Alicante, Spain; \\ gemacorpuscremades@gmail.com \\ 2 Department of Ophthalmology, Vithas Medimar International Hospital, 03016 Alicante, Spain \\ * Correspondence: david.pinyero@ua.es; Tel.: +34-965903400
}

Citation: Corpus, G.; Piñero, D.P. Short-Term Effect of Wearing of Extended Depth-of-Focus Contact Lenses in Myopic Children: A Pilot Study. Appl. Sci. 2022, 12, 431. https://doi.org/10.3390/ app12010431

Academic Editor: Adriano Carnevali

Received: 5 November 2021 Accepted: 31 December 2021 Published: 3 January 2022

Publisher's Note: MDPI stays neutral with regard to jurisdictional claims in published maps and institutional affiliations.

Copyright: () 2022 by the authors. Licensee MDPI, Basel, Switzerland. This article is an open access article distributed under the terms and conditions of the Creative Commons Attribution (CC BY) license (https:/ / creativecommons.org/licenses/by/ $4.0 /)$.

\begin{abstract}
This pseudo-experimental, prospective, and longitudinal pilot study was conducted to characterize the optical and visual changes occurring in the short-term wear of a hydrophilic contact lens (CL) based on extended focus technology (EDOF). A total of 30 eyes of 15 children (age, 6-16 years) were fitted with the EDOF CL Mylo (Mark'ennovy Care SL), performing an exhaustive follow-up for one month evaluating changes in visual acuity (VA), accommodation, binocularity, ocular aberrometry, visual quality, pupillometry, keratometry and biometry. Far and near VA with the CL improved progressively $(p<0.001$ ), obtaining mean final binocular values of $-0.08 \pm 0.01$ and $-0.07 \pm 0.01 \operatorname{LogMAR}$, respectively. There was a mean reduction in the accommodative LAG of $0.30 \mathrm{D}(p<0.001)$, without associated alterations in the magnitude of the phoria and fusional vergences $(p \geq 0.066)$. A controlled but statistically significant increase $(p \leq 0.005)$ of ocular high order aberration (HOA) root mean square (RMS), primary coma RMS, primary spherical aberration Zernike term and secondary astigmatism RMS was found with the CL wear. In conclusion, the EDOF CL evaluated provides adequate visual acuity and quality, with associated increased of several HOAs and a trend to reduction in the accommodative LAG that should be confirmed in future studies.
\end{abstract}

Keywords: myopia; contact lens; extended depth of focus; accommodation; binocular vision; aberrometry

\section{Introduction}

Myopia is the refractive defect in which light rays that enter the eye parallel to the optic axis focus in front of the retina in the unaccommodated eye [1]. This refractive defect induces a blur that can be optically compensated using glasses, contact lenses or through refractive surgery [2]. In general, this refractive error is characterized by excessive elongation of the eyeball, which cannot be treated using traditional techniques and can be associated with serious ocular complications such as premature cataracts, glaucoma, myopic macular degeneration and retinal detachment [3].

Currently, myopia represents the most prevalent ametropia globally, being considered a public health problem. The short-term forecast is that this prevalence will increase, and it is estimated that $50 \%$ of the world population will be myopic in 2050 [4]. This increase could be due to the existence of certain factors such as geographical, genetic or environmental factors that contribute to both the onset and progression of myopia. For this reason, in recent years, a multitude of therapeutic strategies have been investigated to control the progression of myopia and consequently to improve the visual health of the pediatric population. In this sense, various treatments have been developed, including pharmacological options, such as the instillation of specific drugs, and optical aids, such as specially designed ophthalmic lenses and contact lenses (CLs) [5-8]. The optical aids for myopia control are focused on the control of the off-axis or peripheral hyperopic defocus that has shown to be instrumental in the axial elongation of the ocular globe [9-11]. 
Different experiments with animal models have demonstrated that the optical defocus predictably alters eye growth, with specifically hyperopic defocus resulting in increased growth [9-11]. Likewise, the hyperopic defocus which is associated with the presence of a LAG of accommodation during near work [12], including the viewing of handheld electronic devices [13], is also a critical factor in myopia progression. Some authors have even stated that the hyperopic blur can be a risk factor for myopia progression only when the eye has a negative spherical aberration because that is the combination leading to relatively low contrast in the defocused retinal image [12].

In recent years, a great variety of innovative contact lenses and ophthalmic lenses have been developed to reduce off-axis hyperopic defocus and to induce myopic defocus, showing an effective control of the axial elongation of the eye [6-8]. Concerning hydrophilic CLs for myopia control, multifocal designs were initially used that are aimed at inducing a myopic blur on the peripheral retina. Specifically, aspherical center-distance designs and those based on concentric rings showed their effectivity in slowing the growth of axial length (AXL) $[14,15]$. However, these studies did not evaluate the visual function with CLs. Later, specific multifocal CLs were designed for myopia control using aspheric designs [16,17], patterns of concentric rings [18-20] or complex designs based on the combination of an aspherical anterior surface with a double inverse geometry design on the back [21]. Aspheric designs reported a mild decrease in contrast sensitivity, a $0.28 \pm 0.40 \mathrm{D}$ reduction in accommodative response and a significant increase in third and fourth aberrations $(p<0.05)$ [15]. The CL based on concentric rings involved a controlled increase in aberrations and a reduction in contrast sensitivity while maintaining a suitable visual acuity [18-20]. The use of MFCLs with high additions designed for myopia progression control was found to reduce peripheral contrast sensitivity but without impairment of central contrast sensitivity [22]. Recently, a new CL concept for myopia control has been developed based on the principle of extended depth of focus (EDOF). In contrast to multifocal designs, CLs based on this concept are not only aimed at inducing a peripheral myopic defocus to compensate for the potential peripheral hyperopic defocus promoting the axial elongation of the eye. EDOF CLs contain non-monotonic, non-aspheric, and/or aperiodic power profiles, utilizing alterations of spherical aberration as well as of other multiple higher order spherical aberration terms to obtain a relatively stable retinal image quality with minimal susceptibility to variations in the pupil, inherent ocular aberrations and decentration [23]. Therefore, these CLs promote the generation of an acceptable retinal image quality minimally affected by central and peripheral defocus [23]. Currently, the only CL model for myopia control based on this principle is marketed under the name of Mylo (Mark'ennovy Personalize Care SL, Majadahonda, Madrid, Spain), which is based on the use of a non-progressive distribution of power from the center to the periphery, leading to a controlled induction of some high-order aberrations, allowing an increase in the eye depth of focus [24]. This specific myopia control CL has shown a rate slowdown in myopia progression of $32 \%$ and $25 \%$ in terms of spherical refractive equivalent (SE) and AXL, respectively [25].

Despite the abundant scientific evidence on CLs for myopia control, it is mainly focused on the demonstration of their efficacy in terms of the control of SE and AXL changes. However, few studies have exhaustively analyzed the impact of these optical aids on visual acuity, accommodative function and binocularity. Considering the peculiar power profile of myopia control CLs, with significant power modifications across the pupillary area, accommodative and binocular changes are expected. The knowledge of these changes may elucidate the mechanism of action and real visual impact of myopia control CLs. The aim of the current study was to characterize the optical and visual changes occurring in the short term with the EDOF CL Mylo, which has been already demonstrated to be efficacious for myopia control in children in the long term. 


\section{Materials and Methods}

\subsection{Study Design and Patients}

This was a pseudo-experimental, prospective and longitudinal clinical pilot study conducted at the Optometric Clinic of the University of Alicante. The research adhered to the principles of the Declaration of Helsinki and was approved by the ethics committee for medical research of the Health Department of Alicante (General Hospital, Alicante, Spain) (CEIm 2020-048, ISABIAL 200045). Parents of children enrolled in the study were informed about the nature of the investigation and signed a written informed consent. Inclusion criteria for the study were age between 6 and 16 years old, spherical equivalent (SE) between -0.50 and $-8.00 \mathrm{D}$, refractive astigmatism of $0.75 \mathrm{D}$ or below, difference of SE between fellow eyes of $1 \mathrm{D}$ or below, myopia increase of $0.50 \mathrm{D}$ or more in the last 6 months and corrected distance visual acuity (CDVA) of $0.10 \log$ MAR or better. Exclusion criteria were active ocular pathologies, systemic pathologies that affect vision, medications that can produce variations in accommodation, pupil size, tear film or refraction, presence of corneal alterations (ulcers, erosions, infiltrates, hypoesthesia, recurrent bacterial or viral infections, keratoconus or irregular cornea), amblyopia and strabismus.

\subsection{Clinical Protocol}

The study consisted of 5 visits divided into 3 phases: selection and pre-fitting, CL testing and post-fitting follow-up. The tests carried out in each of the study visits are shown in Table 1 . The visual evaluation included measurement of monocular and binocular corrected visual acuity (VA) under mesopic conditions at a distance (6 m, optotype projector) and near distances $(40 \mathrm{~cm}$, Early Treatment Diabetic Retinopathy Study (ETDRS) test). The subjective refractive examination was based on the objective refraction obtained by means of static retinoscopy and subsequently performing the subjective examination in the trial frame following the standard procedure until reaching the maximum positive value providing the maximum visual acuity. The accommodative system was assessed by analyzing the accommodative response through dynamic retinoscopy using two different methodologies, the monocular estimation method (MEM) and the Nott method [26]. Three consecutive measures were obtained and the mean value reported. The evaluation of the binocular system was performed by analyzing three consecutive times the magnitude of the phoria at a distance and near with the cover test (CT), as well as by measuring the horizontal fusional vergences (FVs) using the prism bar, reporting the points of blurring, fusional break and fusional recovery [27]. Both VL and VC were evaluated by performing three measurements in each eye for each VF. Both the base-in (divergence) and base-out (convergence) fusional vergences at a distance and near were measured three times, and the mean value was reported, as recommended [27]. The stereoscopic vision was evaluated by means of the Random Dot $1 S$ Stereo Acuity Test (Vision Assessment Corporation, Elk Grove Village, IL, USA).

The slit lamp biomicroscopic examination was used in the first visit to examine the anterior segment and rule out any ocular pathology. In the CL testing, this examination allowed the clinician to assess the centration and movement of the CL to optimize its fitting. In addition, in the post-fitting follow-up, the slit lamp examination was needed to check the anterior segment health and to detect any potential complication that could be related to the CL wear, such as the presence of limbal vascularization, punctata keratitis of the formation of deposits over the CL surface. 
Table 1. Clinical protocol followed in the current study. Abbreviations: CL, contact lens; MEM, monocular estimation method. Abbreviations: CL, contact lens; MEM, monocular estimation method.

\begin{tabular}{|c|c|c|c|c|c|}
\hline \multirow[b]{2}{*}{ Visit } & \multirow{2}{*}{$\begin{array}{c}\text { Pre-Fitting } \\
1\end{array}$} & \multirow{2}{*}{$\begin{array}{c}\text { CL Testing } \\
2\end{array}$} & \multicolumn{3}{|c|}{ Post-Fitting Follow-Up } \\
\hline & & & 3 & 4 & 5 \\
\hline & First visit & CL testing & 1 day & 15 days & 30 days \\
\hline $\begin{array}{l}\text { Objective refraction } \\
\text { (retinoscopy) }\end{array}$ & $X$ & $X$ & $\mathrm{X}$ & $X$ & $X$ \\
\hline Subjective refraction & $X$ & & & & \\
\hline Over-refraction with CL & & $x$ & $\mathrm{X}$ & $X$ & $x$ \\
\hline $\begin{array}{l}\text { Accommodative response } \\
\text { (MEM/Nott) }\end{array}$ & $X$ & & & $X$ & $X$ \\
\hline Cover test (far/near) & $x$ & & & $x$ & $x$ \\
\hline $\begin{array}{l}\text { Fusional vergences } \\
\text { (far/near) }\end{array}$ & $X$ & & & & $X$ \\
\hline Stereopsis & $x$ & & & & $x$ \\
\hline $\begin{array}{l}\text { Photic phenomena } \\
\text { (questionnaire) }\end{array}$ & $X$ & & & & $X$ \\
\hline Slit lamp biomicroscopy & $x$ & $x$ & $X$ & $x$ & $x$ \\
\hline $\begin{array}{l}\text { Corneal topography } \\
\left(\mathrm{VX} 120++^{\odot}\right)\end{array}$ & $X$ & $X$ & $x$ & $x$ & $x$ \\
\hline $\begin{array}{l}\text { Ocular aberrometry } \\
\left(\mathrm{VX} 120+{ }^{\odot}\right)\end{array}$ & $x$ & $x$ & $x$ & $X$ & $x$ \\
\hline $\begin{array}{l}\text { Optical biometry } \\
\left.\text { (IOL-Master }^{(}\right)\end{array}$ & $X$ & & & & $x$ \\
\hline
\end{tabular}

Subjective vision quality was assessed with a self-developed questionnaire asking about the perception of three photic phenomena, halos, glare and starbursts. Specifically, subjects were asked about the frequency (never, occasionally, frequently, often) and level of bothersomeness (none, mild, moderate, severe) of these three photic phenomena. The Visionix VX120 + multi-diagnostic platform (Luneau Technology, Chartres, France) was used to obtain keratometric data, corneal diameter, corneal pachymetry, anterior chamber depth (ACD), pupillometry and total ocular aberrations for 2 pupil apertures ( 3 and $5 \mathrm{~mm}$ ). The IOL Master 500 (Carl Zeiss Meditec, Jena, Germany) was used to obtain the measurement of $\mathrm{AXL}$, performing at least 6 consecutive measurements per eye and ensuring that all of them have an associated value of SNR (signal-to-noise ratio) of more than 3 units.

All visits and measurements were performed during the same period of the day, between 17:30 and 20:30 p.m.

\subsection{Extended Depth-of-Focus Contact Lens}

The EDOF CL used in the current study was Mylo (Mark'ennovy Personalize Care SL, Majadahonda, Madrid, Spain), which is a silicone hydrogel CL (Filcon 5B) of monthly replacement. The material has a high-water content $(75 \%)$ and a low coefficient of friction $(0.02)$. This CL can be manufactured with a great variety of radius of curvature $(7.10-9.80 \mathrm{~mm})$, diameter (13.50-15.50 mm) and negative optical power $(0.25-15.00 \mathrm{D})$ to customize the fitting. This CL has been specifically designed for myopia control and has been approved by the Spanish Agency of Medication for such a purpose. From the optical perspective, it is based on the use of a distribution of power from the center to the periphery, which is not progressive, especially in the optical zone that includes non-monotonic and aperiodic series of variation of powers $[23,24,28]$. This complex optical surface leads to a controlled induction of high-order aberrations, especially primary $\left(\mathrm{Z}_{4}{ }^{0}\right)$ and secondary $\left(\mathrm{Z}_{6}{ }^{0}\right)$ spherical aberration, allowing an enlargement of the depth of focus and consequently the relative maintenance of its optical behavior under different circumstances (pupil aperture, centration, corneal optical properties). For the generation of these complex surfaces, proprietary non-linear optimization algorithms for high-order aberrations are used [23,24,28]. 


\subsection{Statistical Analysis}

Statistical analysis was performed with the SPSS version 25.0 software (IBM, Armonk, NY, USA). Due to the low sample size, non-parametric statistics were used. The chi-square test was used for the assessment of the statistical significance of differences for qualitative variables, whereas the Friedman and Wilcoxon tests were used for the quantitative variables. Specifically, the Friedman test was used when analyzing differences in variables measured in more than two visits, whereas the Wilcoxon test was used for the comparisons between pairs. Likewise, the Wilcoxon test was also used for post hoc comparisons by pairs after Friedman's analysis, using the Bonferroni correction to adjust the experimental error rate. Finally, the relationship between different clinical variables was also analyzed by calculating the Spearman correlation coefficient. All statistical tests were 2-tailed, and $p$-values less than 0.05 were considered as statistically significant.

As the sample of patients recruited was small, the statistical power associated with each change that was found to be statistically significant was calculated a posteriori using the software PS Power and Sample Size Calculations Version 3.0 (Vanderbilt University, Nashville, TN, USA). This software can be used to calculate the statistical power associated with different types of statistical tests using the method described by Dupont and Plummer [29]. For the monocular visual acuity analysis, only data from the right eye were selected.

\section{Results}

A total of 30 eyes from 15 Caucasian subjects with an average age of $13.3 \pm 0.7$ years were considered in this pilot study. The sample was distributed according to gender as follows: six boys (40\%) and nine girls (60\%). Of the 15 patients who started the study, 13 complied with all the visits and established requirements, while two dropped out of the study. Therefore, the rate of loss to follow-up was 13\%, leaving for the analysis a complete follow-up of 13 patients.

\subsection{EDOF CL Use Improved VA}

In terms of VA with the CL, a statistically significant improvement $(p<0.001)$ was observed over time, both monocularly (right eye) and binocularly (Table 2 and Figure 1). After the CL testing visit, an improvement trend was observed in the monocular and binocular far and near VA, but without reaching statistical significance $(p \geq 0.168)$. However, significant improvements were detected in all VAs measured at 15 and 30 days of CL wear compared to the baseline value $(p \leq 0.042)$ (Table 2$)$. There was a significant correlation $(p<0.001)$ between monocular far VA with CL and monocular near VA with CL on the day of CL fitting $(r=0.644)$, after 1 day of $C L$ wear $(r=0.790)$ and after 15 days of CL use $(r=0.730)$.

Table 2. Visual acuity data measured at the different visits of the current clinical study. Abbreviations: $\mathrm{SD}$, standard deviation; $\mathrm{CL}$, contact lens; VA, visual acuity.

\begin{tabular}{|c|c|c|c|c|c|}
\hline $\begin{array}{c}\text { Mean } \pm \text { SD } \\
\text { Median (Range) }\end{array}$ & CL Testing Visit & 1 Day & 15 Days & 30 Days & $\begin{array}{c}p \text {-Value } \\
\text { (CL Testing- } \\
30 \text { Days) }\end{array}$ \\
\hline $\begin{array}{c}\text { Monocular far VA } \\
\text { with CL }\end{array}$ & $\begin{array}{c}0.03 \pm 0.05 \\
0.00(-0.10 \text { to } 0.15)\end{array}$ & $\begin{array}{c}0.01 \pm 0.06 \\
0.00(-0.10 \text { to } 0.10)\end{array}$ & $\begin{array}{c}-0.03 \pm 0.05 \\
0.00(-0.10 \text { to } 0.05)\end{array}$ & $\begin{array}{c}-0.07 \pm 0.05 \\
-0.10(-0.10 \text { to } \\
0.05)\end{array}$ & $<0.001$ \\
\hline $\begin{array}{c}\text { Binocular far VA } \\
\text { with CL }\end{array}$ & $\begin{array}{c}0.00 \pm 0.04 \\
0.00(-0.10 .0 .10)\end{array}$ & $\begin{array}{c}-0.03 \pm 0.07 \\
0.00(-0.10 .0 .05)\end{array}$ & $\begin{array}{c}-0.05 \pm 0.05 \\
-0.10(-0.10 .0 .00)\end{array}$ & $\begin{array}{c}-0.08 \pm 0.04 \\
-0.10(-0.10 .0 .00)\end{array}$ & $<0.001$ \\
\hline $\begin{array}{l}\text { Monocular near } \\
\text { VA with CL }\end{array}$ & $\begin{array}{c}0.06 \pm 0.06 \\
0.10(-0.10 .0 .15)\end{array}$ & $\begin{array}{c}0.03 \pm 0.05 \\
0.05(-0.10 .0 .10)\end{array}$ & $\begin{array}{c}-0.03 \pm 0.06 \\
0.00(-0.10 .0 .05)\end{array}$ & $\begin{array}{c}-0.05 \pm 0.06 \\
-0.10(-0.10 .0 .10)\end{array}$ & $<0.001$ \\
\hline $\begin{array}{l}\text { Binocular near VA } \\
\text { with CL }\end{array}$ & $\begin{array}{c}0.02 \pm 0.06 \\
0.00(-0.10 .0 .10)\end{array}$ & $\begin{array}{c}-0.01 \pm 0.06 \\
0.00(-0.10 .0 .10)\end{array}$ & $\begin{array}{c}-0.05 \pm 0.05 \\
0.00(-0.10 .0 .00)\end{array}$ & $\begin{array}{c}-0.07 \pm 0.05 \\
-0.10(-0.10 .0 .00)\end{array}$ & $<0.001$ \\
\hline
\end{tabular}




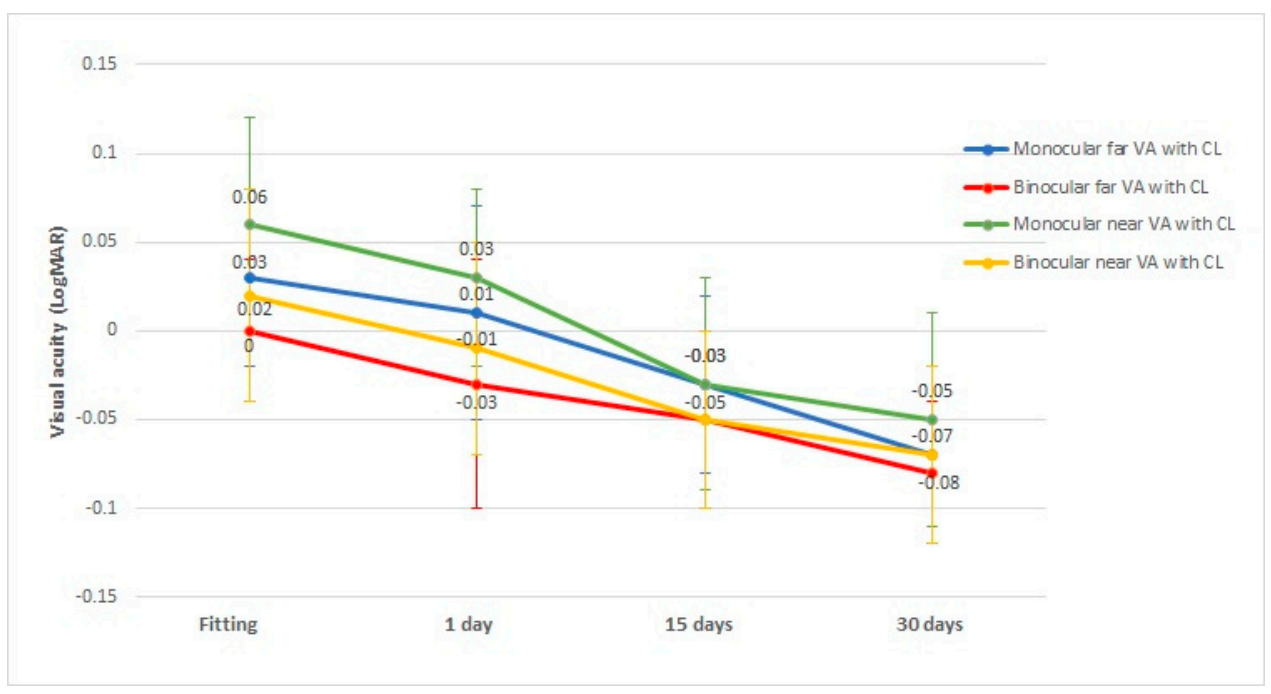

Figure 1. Changes in the visual acuity with contact lens measured at the different visits of the current clinical study. Abbreviations: CL, contact lens; VA, visual acuity.

Mean monocular and binocular best spectacle-corrected pre-fitting visual acuities were $-0.02 \pm 0.04$ and $-0.04 \pm 0.06 \log \mathrm{MAR}$, respectively, when measured at a distance. For near, mean monocular and binocular best spectacle-corrected pre-fitting visual acuities were $-0.02 \pm 0.05$ and $-0.06 \pm 0.05 \log$ MAR, respectively. There was a statistically significant reduction in the visual acuity when comparing these spectacle-corrected values with those obtained with the CL in the first testing $(p \leq 0.004)$. However, there were no significant differences in monocular and binocular distance and near visual acuities when comparing those values measured with spectacle before the fitting and those measured with the CL at the end of the follow-up ( $p \geq 0.34$ ).

\subsection{EDOF CL Use Modified the Accommodative Response}

Three consecutive measurements were obtained of the LAG of accommodation, obtaining a within-subject standard deviation of 0.08 and $0.06 \mathrm{D}$ for the MEM and Nott techniques. The accommodative response values obtained with both MEM and Nott methodologies showed a significant reduction with the use of the EDOF CL $(p<0.001)$. A mean accommodative delay (LAG) of $0.68 \pm 0.22$ and $0.72 \pm 0.23 \mathrm{D}$ was measured in the baseline visit with the MEM and Nott techniques, respectively. After 30 days of CL wear, the mean accommodative LAG decreased to $0.32 \pm 0.17$ and $0.37 \pm 0.20 \mathrm{D}$ with the MEM and Nott techniques, respectively. Figure 2 shows the decrease in the accommodative delay.

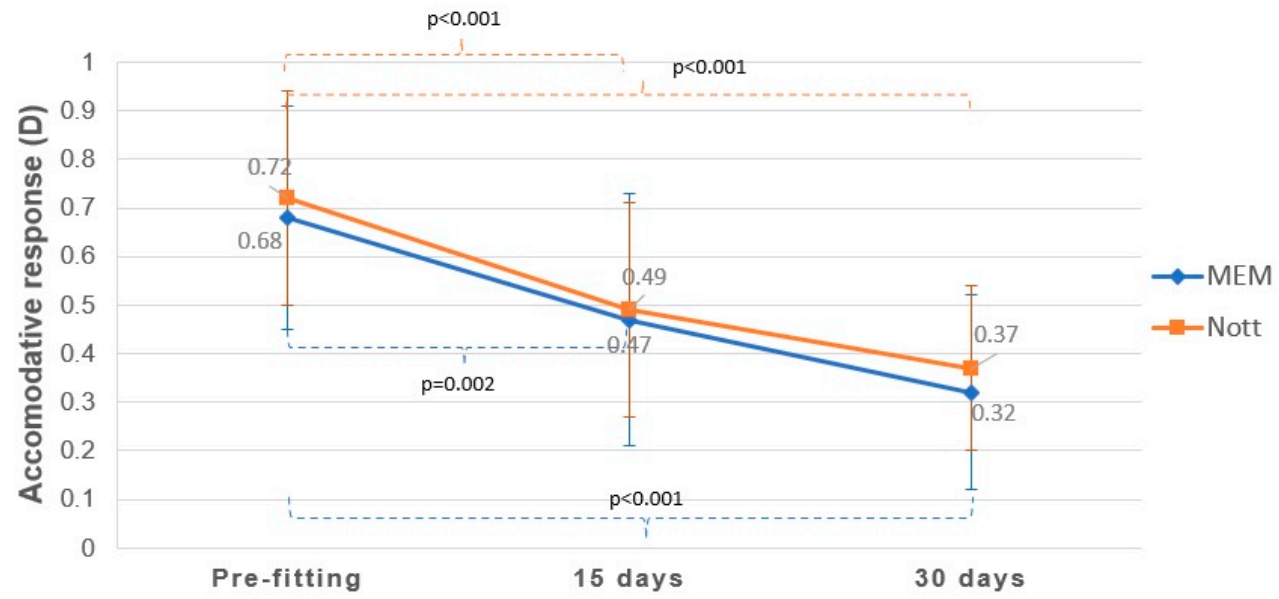

Figure 2. Changes in the accommodative response measured with the MEM and Nott techniques during the first month of contact lens wear. 


\subsection{EDOF CL Use Did Not Affect Binocular Vision}

Three consecutive measurements were obtained of the measurement of the phoria, obtaining a within-subject standard deviation of 0.9 and $1.5 \Delta$ for distance and near. No significant variations were found in the measurement of the phoria with the cover test after the use of the CL ( $p=0.368)$, although there was a slight tendency towards an increase in the exophoria at near (pre-fitting $-2.13 \pm 0.90 \Delta$ vs. 30 days of CL wear $-2.23 \pm 1.00 \Delta$, $p=0.097$ ). Negative and positive FV blurring, break and recovery points did not experience significant variations with the use of the CL $(p \geq 0.106)$, although an increasing trend was observed in the positive FV parameters measured at near (pre-fitting: blur $24.93 \pm 4.17 \Delta$, break $34.20 \pm 1.96 \Delta$, recovery $31.60 \pm 2.46 \Delta$ vs. 30 days of CL use: blur $31.00 \pm 4.27 \Delta$, break $36.92 \pm 1.65 \Delta$, recovery $36.15 \pm 2.05 \Delta, p=0.066$ ) (Table 3).

Table 3. Fusional vergence data at a distance and near obtained before the fitting and 30 days after contact lens wear. Abbreviations: SD, standard deviation; CL, contact lens; NFV, negative fusional vergence; PFV, positive fusional vergence.

\begin{tabular}{|c|c|c|c|c|}
\hline \multicolumn{2}{|c|}{$\begin{array}{c}\text { Mean } \pm \text { SD } \\
\text { Median (Range) }\end{array}$} & Pre-Fitting & 30 Days of CL Use & $p$-Value \\
\hline \multirow{2}{*}{ Far NFV $(\Delta)$} & Break & $\begin{array}{c}8.53 \pm 0.46 \\
8.00(6.00 \text { to } 12.00)\end{array}$ & $\begin{array}{c}8.61 \pm 0.57 \\
8.00(6.00 \text { to } 14.00)\end{array}$ & 0.480 \\
\hline & Recovery & $\begin{array}{c}6.53 \pm 0.46 \\
6.00(4.00 \text { to } 10.00)\end{array}$ & $\begin{array}{c}6.61 \pm 0.57 \\
6.00(4.00 \text { to } 12.00)\end{array}$ & 0.480 \\
\hline \multirow{3}{*}{ Far PFV $(\Delta)$} & Blur & $\begin{array}{c}12.13 \pm 1.73 \\
12.00(0.00 \text { to } 12.00)\end{array}$ & $\begin{array}{c}12.46 \pm 1.86 \\
14.00(0.00 \text { to } 20.00)\end{array}$ & 0.595 \\
\hline & Break & $\begin{array}{c}20.60 \pm 1.94 \\
20.00(6.00 \text { to } 35.00)\end{array}$ & $\begin{array}{c}20.54 \pm 1.72 \\
24.00(10.00 \text { to } 30.00)\end{array}$ & 0.888 \\
\hline & Recovery & $\begin{array}{c}15.73 \pm 1.25 \\
18.00(4.00 \text { to } 20.00)\end{array}$ & $\begin{array}{c}17.70 \pm 2.00 \\
18.00(8.00 \text { to } 35.00)\end{array}$ & 0.292 \\
\hline \multirow{3}{*}{ Near NFV $(\Delta)$} & Blur & $\begin{array}{c}8.23 \pm 1.35 \\
8.00(0.00 \text { to } 16.00)\end{array}$ & $\begin{array}{c}9.08 \pm 1.70 \\
10.00(0.00 \text { to } 18.00)\end{array}$ & 0.531 \\
\hline & Break & $\begin{array}{c}13.73 \pm 0.91 \\
12.00(8.00 \text { to } 20.00)\end{array}$ & $\begin{array}{c}16.38 \pm 1.26 \\
16.00(10.00 \text { to } 25.00)\end{array}$ & 0.106 \\
\hline & Recovery & $\begin{array}{c}11.47 \pm 0.74 \\
10.00(6.00 \text { to } 16.00)\end{array}$ & $\begin{array}{c}13.23 \pm 1.29 \\
14.00(4.00 \text { to } 20.00)\end{array}$ & 0.124 \\
\hline \multirow{3}{*}{ Near PFV $(\Delta)$} & Blur & $\begin{array}{c}24.93 \pm 4.17 \\
20.00(0.00 \text { to } 40.00)\end{array}$ & $\begin{array}{c}31.00 \pm 4.27 \\
40.00(0.00 \text { to } 40.00)\end{array}$ & 0.066 \\
\hline & Break & $\begin{array}{c}34.20 \pm 1.96 \\
40.00(18.00 \text { to } 40.00)\end{array}$ & $\begin{array}{c}36.92 \pm 1.65 \\
40.00(25.00 \text { to } 40.00)\end{array}$ & 0.066 \\
\hline & Recovery & $\begin{array}{c}31.60 \pm 2.46 \\
35.00(14.00 \text { to } 40.00)\end{array}$ & $\begin{array}{c}36.15 \pm 2.05 \\
40.00(20.00 \text { to } 40.00)\end{array}$ & 0.066 \\
\hline
\end{tabular}

Mean magnitude of stereoacuity at the beginning of the study was $23.17 \pm 1.51$ arc seconds. At the last visit of the study, a mean stereoacuity value of $21.27 \pm 2.26$ arc seconds was found. This change in stereoacuity did not reach statistical significance $(p=0.145)$, suggesting that the CL does not interfere with stereoscopic vision.

\subsection{EDOF CL Use Induced a Controlled Increase in High Order Aberrations (HOAs)}

With the use of the $\mathrm{CL}$, a controlled increase in most aberrometric coefficients was observed, as shown in Table 4. Specifically, for 3 and $5 \mathrm{~mm}$ pupils, statistically significant changes were detected in ocular HOA root mean square (RMS), primary coma RMS, primary spherical aberration Zernike term and secondary astigmatism RMS $(p \leq 0.005)$ with the CL wear. In contrast, no significant changes were detected in trefoil RMS (3 mm, $p=0.060 ; 5 \mathrm{~mm}, p=0.146$ ). The significant changes in ocular HOA RMS, primary coma RMS, primary spherical aberration Zernike term and secondary astigmatism RMS were detected on the first day of CL wear $(p \leq 0.020)$, with no significant changes during the 
remaining post-fitting follow-up visits $(p \geq 0.120)$, except for the change in secondary astigmatism RMS between the 1-day and 15-day CL wear visits $(p<0.001)$.

Table 4. Ocular aberrometric data measured at baseline and during the post-fitting period in the current study. Abbreviations: SD, standard deviation; HOA, high order aberration; RMS, root mean square.

\begin{tabular}{|c|c|c|c|c|c|c|}
\hline \multicolumn{2}{|c|}{$\begin{array}{c}\text { Mean } \pm \text { SD } \\
\text { Median (Range) }\end{array}$} & Pre-Fitting & 1 Day & 15 Days & 30 Days & $p$-Value \\
\hline \multirow{2}{*}{$\begin{array}{l}\text { HOA RMS } \\
\qquad(\mu \mathrm{m})\end{array}$} & $3 \mathrm{~mm}$ & $\begin{array}{c}0.04 \pm 0.00 \\
0.04(0.02 \text { to } 0.07)\end{array}$ & $\begin{array}{c}0.07 \pm 0.00 \\
0.07(0.04 \text { to } 0.11)\end{array}$ & $\begin{array}{c}0.07 \pm 0.01 \\
0.07(0.04 \text { to } 0.13)\end{array}$ & $\begin{array}{c}0.08 \pm 0.01 \\
0.07(0.04 \text { to } 0.18)\end{array}$ & $<0.001$ \\
\hline & $5 \mathrm{~mm}$ & $\begin{array}{c}0.17 \pm 0.12 \\
0.16(0.09 \text { to } 0.34)\end{array}$ & $\begin{array}{c}0.23 \pm 0.01 \\
0.22(0.13 \text { to } 0.34)\end{array}$ & $\begin{array}{c}0.24 \pm 0.02 \\
0.22(0.05 \text { to } 0.44)\end{array}$ & $\begin{array}{c}0.23 \pm 0.02 \\
0.21(0.05 \text { to } 0.43)\end{array}$ & $<0.001$ \\
\hline \multirow{2}{*}{$\begin{array}{l}\text { Primary coma RMS } \\
\qquad(\mu \mathrm{m})\end{array}$} & $3 \mathrm{~mm}$ & $\begin{array}{c}0.02 \pm 0.00 \\
0.02(0.01 \text { to } 0.07)\end{array}$ & $\begin{array}{c}0.05 \pm 0.00 \\
0.05(0.01 \text { to } 0.08)\end{array}$ & $\begin{array}{c}0.05 \pm 0.01 \\
0.05(0.02 \text { to } 0.13)\end{array}$ & $\begin{array}{c}0.06 \pm 0.01 \\
0.05(0.01 \text { to } 0.17)\end{array}$ & $<0.001$ \\
\hline & $5 \mathrm{~mm}$ & $\begin{array}{c}0.11 \pm 0.01 \\
0.09(0.02 \text { to } 0.32)\end{array}$ & $\begin{array}{c}0.15 \pm 0.01 \\
0.16(0.05 \text { to } 0.26)\end{array}$ & $\begin{array}{c}0.14 \pm 0.02 \\
0.11(0.02 \text { to } 0.42)\end{array}$ & $\begin{array}{c}0.13 \pm 0.16 \\
0.13(0.04 \text { to } 0.41)\end{array}$ & 0.008 \\
\hline \multirow{2}{*}{$\begin{array}{l}\text { SA } \\
(\mu \mathrm{m})\end{array}$} & $3 \mathrm{~mm}$ & $\begin{array}{c}0.00 \pm 0.00 \\
0.00(-0.02 \text { to } 0.02)\end{array}$ & $\begin{array}{c}-0.01 \pm 0.00 \\
-0.01(-0.04 \text { to } 0.01)\end{array}$ & $\begin{array}{c}-0.01 \pm 0.00 \\
-0.01(-0.06 \text { to } 0.02)\end{array}$ & $\begin{array}{c}-0.01 \pm 0.00 \\
-0.01(-0.03 \text { to } 0.01)\end{array}$ & $<0.001$ \\
\hline & $5 \mathrm{~mm}$ & $\begin{array}{c}0.00 \pm 0.01 \\
0.02(-0.14 \text { to } 0.09)\end{array}$ & $\begin{array}{c}-0.07 \pm 0.01 \\
-0.06(-0.20 \text { to } 0.07)\end{array}$ & $\begin{array}{c}-0.08 \pm 0.02 \\
-0.07(-0.30 \text { to } 0.05)\end{array}$ & $\begin{array}{c}-0.07 \pm 0.01 \\
-0.07(-0.16 \text { to } 0.00)\end{array}$ & $<0.001$ \\
\hline \multirow{2}{*}{$\begin{array}{c}\text { Secondary } \\
\text { astigmatism RMS } \\
(\mu \mathrm{m})\end{array}$} & $3 \mathrm{~mm}$ & $\begin{array}{c}0.01 \pm 0.00 \\
0.01(0.00 \text { to } 0.02)\end{array}$ & $\begin{array}{c}0.01 \pm 0.00 \\
0.01(0.00 \text { to } 0.03)\end{array}$ & $\begin{array}{c}0.01 \pm 0.00 \\
0.01(0.00 \text { to } 0.04)\end{array}$ & $\begin{array}{c}0.01 \pm 0.00 \\
0.01(0.00 \text { to } 0.04)\end{array}$ & 0.005 \\
\hline & $5 \mathrm{~mm}$ & $\begin{array}{c}0.03 \pm 0.00 \\
0.02(0.00 \text { to } 0.10)\end{array}$ & $\begin{array}{c}0.05 \pm 0.01 \\
0.04(0.01 \text { to } 0.10)\end{array}$ & $\begin{array}{c}0.04 \pm 0.00 \\
0.05(0.01 \text { to } 0.08)\end{array}$ & $\begin{array}{c}0.05 \pm 0.01 \\
0.04(0.00 \text { to } 0.20)\end{array}$ & $<0.001$ \\
\hline \multirow{2}{*}{$\begin{array}{l}\text { Trefoil RMS } \\
\qquad(\mu \mathrm{m})\end{array}$} & $3 \mathrm{~mm}$ & $\begin{array}{c}0.02 \pm 0.00 \\
0.02(0.00 \text { to } 0.06)\end{array}$ & $\begin{array}{c}0.03 \pm 0.00 \\
0.03(0.00 \text { to } 0.07)\end{array}$ & $\begin{array}{c}0.04 \pm 0.01 \\
0.03(0.00 \text { to } 0.20)\end{array}$ & $\begin{array}{c}0.04 \pm 0.00 \\
0.03(0.01 \text { to } 0.08)\end{array}$ & 0.060 \\
\hline & $5 \mathrm{~mm}$ & $\begin{array}{c}0.09 \pm 0.01 \\
0.08(0.01 \text { to } 0.23)\end{array}$ & $\begin{array}{c}0.10 \pm 0.01 \\
0.09(0.02 \text { to } 0.25)\end{array}$ & $\begin{array}{c}0.11 \pm 0.01 \\
0.09(0.01 \text { to } 0.33)\end{array}$ & $\begin{array}{c}0.10 \pm 0.01 \\
0.09(0.03 \text { to } 0.21)\end{array}$ & 0.146 \\
\hline
\end{tabular}

\subsection{EDOF CL Use Was Associated with Minimal Subjective Complaints}

Occasional or frequent perception of glare was reported before the fitting by $13.4 \%$ (2 of 15) of participants, whereas this percentage increased to $30.8 \%$ (4 of 13) after 30 days of CL wear $(p=0.902)$ (Figure 3$)$. Regarding halos, they were perceived by $6.7 \%$ ( 1 of 15$)$ and $23.1 \%$ ( 3 of 13 ) of patients before and after 30 days of CL wear $(p=0.051)$ (Figure 3 ). Starbursts were perceived occasionally or frequently by $86.7 \%$ (13 of 15$)$ and $84.7 \%$ (11 of 13) of patients before and after 30 days of CL wear $(p=0.087)$ (Figure 3$)$. Most subjects described these three photic phenomena as not bothersome before and at the end of the follow-up (glare: $93.3 \%$ vs. $76.9 \%, p=0.569$; halos: $93.3 \%$ vs. $84.6 \%, p=0.657$; starbursts: $53.3 \%$ vs. $53.8 \%, p=0.162$ ) (Figure 4 ).

\subsection{EDOF CL Use Changed the Pupillary Dynamics and Some Biometric Parameters}

Pupillary size measured under scotopic $(p=0.203)$ and mesopic conditions $(p=0.227)$ did not experience a significant modification with the use of the CL. However, a reduction was observed in the pupil size measured under photopic conditions, obtaining a mean value of $4.18 \pm 0.08 \mathrm{~mm}$ before fitting and $3.99 \pm 0.07 \mathrm{~mm}$ after 30 days of CL use ( $p=0.024)$.

At the end of the study, no significant variations were found in terms of mean keratometry $(7.80 \pm 0.05$ vs. $7.86 \pm 0.05 \mathrm{~mm}, p=0.329)$ or AXL ( $24.50 \pm 0.17$ vs. $24.54 \pm 0.20 \mathrm{~mm}$, $p=0.285$ ), indicating the absence of molding or modification of the corneal geometry after the use of CL and progression of myopia during the study period. However, a statistically significant reduction was found in the anterior chamber depth, changing from a mean value of $3.40 \pm 0.03 \mathrm{~mm}$ at the pre-fitting visit to $3.34 \pm 0.04 \mathrm{~mm}$ after 30 days of CL use $(p=0.022)$.

Regarding the central corneal thickness (CCT), the change was close to the limit of statistical significance $(p=0.053)$. Specifically, CCT increased from a mean value of $536.80 \pm 5.88 \mu \mathrm{m}$ before CL fitting to a mean value of $543.54 \pm 6.52 \mu \mathrm{m}$ after 30 days of $C L$ use. 


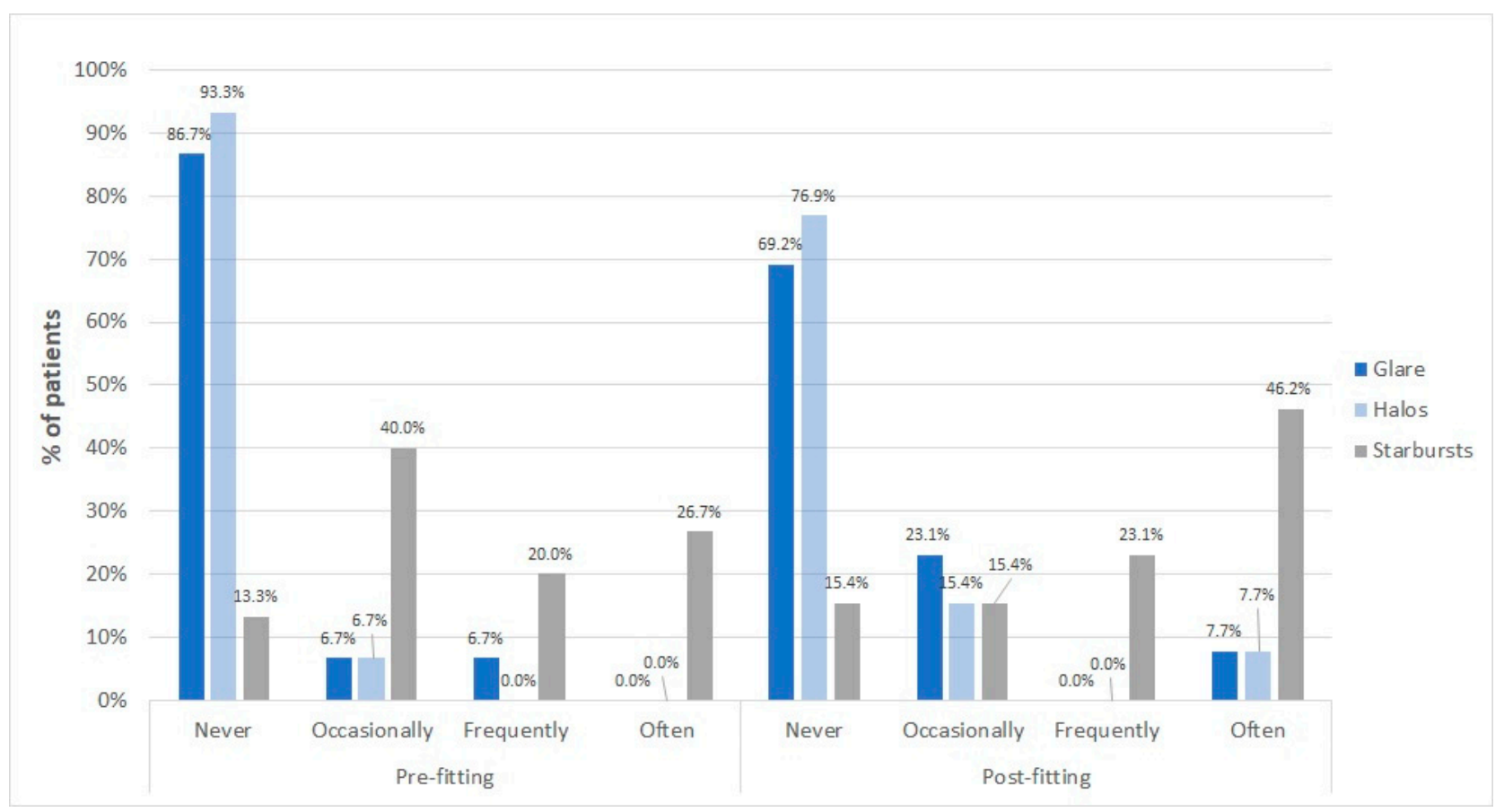

Figure 3. Distribution of the frequency of perception of glare, halos and starbursts before (with 15 patients) and after 30 days of CL wear (with 13 patients) in the sample evaluated.

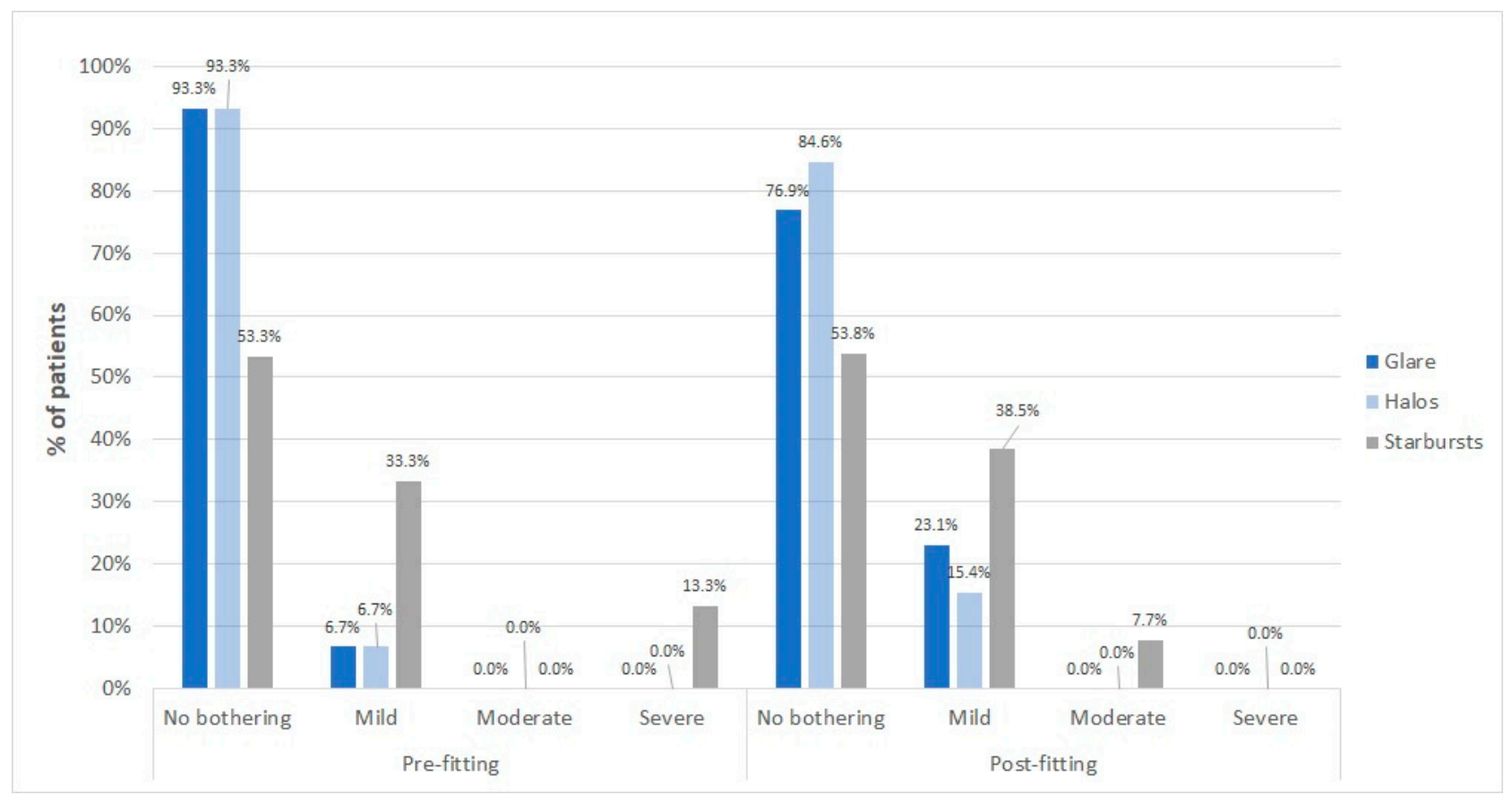

Figure 4. Distribution of the level of bothersomeness of glare, halos and starbursts perceived by patients before (with 15 patients) and after 30 days of CL wear (with 13 patients) in the sample evaluated.

\subsection{EDOF CL Use Did Not Cause Severe Complications}

No severe ocular complications were reported during the period of CL use. Likewise, no subject dropped out of the study due to discomfort associated with the CL wear. In the fitting process, three subjects $(20 \%)$ required changes in the parameters of the first CL tested due to centration and movement problems (change of base curve). These changes in 
the CL were applied at the first visit after wearing it for at least $30 \mathrm{~min}$. Only the data with the appropriate fitting (last CL) were considered in the analysis.

\subsection{Sample Size Calculations}

Table 5 shows the statistical power calculations associated with the analysis of those variables showing statistically significant changes. As shown, the most limited statistical power was associated with the analysis of changes in primary coma RMS for a $5 \mathrm{~mm}$ pupil $(14.0 \%)$.

Table 5. Statistical power calculations associated with the analysis of those variables showing statistically significant changes. Abbreviations: $\alpha$, type I error probability (probability of falsely rejecting the null hypothesis; $\delta$, difference between means; $\sigma$, standard deviation of difference in the response of matched pairs; n, number of subjects; SP, statistical power; MEM, monocular estimation method; HOA, high order aberration; RMS, root mean square; SA, spherical aberration; $A C D$, anterior chamber depth.

\begin{tabular}{cccccc}
\hline & $\alpha$ & $\delta$ & $\sigma$ & $\mathbf{n}$ & SP \\
\hline Monocular far VA with CL (testing day-30 days) & 0.05 & -0.10 & 0.05 & 13 & $99.9 \%$ \\
Binocular far VA with CL (testing day-30 days) & 0.05 & -0.08 & 0.04 & 13 & $99.9 \%$ \\
Monocular near VA with CL (testing day-30 days) & 0.05 & -0.11 & 0.08 & 13 & $99.9 \%$ \\
Binocular near VA with CL (testing day-30 days) & 0.05 & -0.09 & 0.05 & 13 & $99.2 \%$ \\
MEM & 0.05 & -0.41 & 0.22 & 13 & $99.9 \%$ \\
Nott retinoscopy & 0.05 & -0.40 & 0.32 & 13 & $98.1 \%$ \\
HOA RMS 3 mm & 0.05 & 0.04 & 0.03 & 13 & $98.9 \%$ \\
HOA RMS 5 mm & 0.05 & 0.06 & 0.07 & 13 & $81.0 \%$ \\
Primary coma RMS 3 mm & 0.05 & 0.03 & 0.03 & 13 & $91.0 \%$ \\
Primary coma RMS 5 mm & 0.05 & 0.02 & 0.07 & 13 & $14.0 \%$ \\
SA 3 mm & 0.05 & -0.01 & 0.01 & 13 & $91.0 \%$ \\
SA 5 mm & 0.05 & -0.07 & 0.07 & 13 & $91.0 \%$ \\
Secondary astigmatism RMS 3 mm & 0.05 & 0.01 & 0.01 & 13 & $91.0 \%$ \\
Secondary astigmatism RMS 5 mm & 0.05 & 0.02 & 0.05 & 13 & $24.0 \%$ \\
Photopic pupil size & 0.05 & -0.17 & 0.37 & 13 & $30.7 \%$ \\
ACD & 0.05 & -0.04 & 0.08 & 13 & $35.8 \%$ \\
\hline
\end{tabular}

\section{Discussion}

Most of the published studies on the evaluation of CLs for myopia control are focused on determining their efficacy for slowing the eyeball elongation according to changes in parameters such as SE and AXL. However, few of them have analyzed the real impact of the different designs of myopia control CLs on aspects such as visual acuity, visual quality or binocularity. In the current study, it was observed that the VA obtained with the EDOF CL evaluated improved as its wearing time increased. Indeed, there was an initial worsening of the VA once the lens was fitted for the first time, but the level of visual acuity was increased progressively during the first month of wearing until reaching the same level as with spectacles. This suggests that there is a period of visual adaptation with this CL of a few days (within the first 15 days of CL wear) and children fitted with this model of CL should be informed about this. On the first day of wear, the monocular far and near VA values measured in the current samples were close to those reported by Tilia et al. [30] who evaluated the same EOF CL (distance: $0.03 \pm 0.06$; near: $0.02 \pm 0.08$ ). In binocular tests, the study by Chamberlain et al. [31] using CLs with a concentric ring design reported slightly higher VA values for both far and near distances during the very early CL wear. Only the studies by Kollbaum et al. [32] and Sankaridurg et al. [25] carried out a post-fitting follow-up of VA, not obtaining a significant visual evolution with the CL wear. Another aspect not considered in previous studies and that was analyzed in our study was the correlation between near and far VA. We found a significant positive correlation of moderate strength in the first three follow-up visits. This indicates that those children having a worse far vision at the beginning of the use of the EDOF CL evaluated tended 
to also have a worse near vision, and therefore there is a potential global limitation of the visual function of children fitted with this CL during the first days of use. Afterwards, the VA with this CL progressively improves with its use, obtaining near and far VAs like those obtained with spectacles. Several factors may have contributed to this, including some level of neuroadaptation, which has been demonstrated to be initiated during the first weeks after the use of a multifocal optical device [33] or the stabilization of the CL with the wearing period. In any case, this potential visual improvement with the CL wear must be considered with care as the mean value obtained of one line of visual acuity improvement could be also due to the inherent variability of the visual acuity measurements. For this reason, changes in VA with this CL must be investigated further in future trials with larger sample sizes to extract more consistent conclusions.

Concerning the accommodative response, a trend to a reduction in the accommodative response was observed, with a mean value of change of $0.30 \mathrm{D}$ at the end of the followup. With EDOF CLs, only two previous studies evaluated the accommodative function, reporting a good accommodation performance [30] and an improvement in accommodative flexibility [34], but not measuring specifically the accommodative response. However, other studies have evaluated the accommodative response after the use of other designs of myopia control CLs. Pauné et al. [17] found a decrease in the accommodative LAG after one year of wear of a radial refractive gradient CL, while Ruiz-Pomeda et al. [19] did not find significant variations in the accommodative LAG after two years of wear of a concentric ring design CL, although it should be considered that measurements in this last study were taken without the CL. According to the data obtained in the current series, the EDOF CL evaluated seems to induce some changes in the accommodative response in the short term, although with limited clinical relevance (small magnitude). It is well-known that the use of an addition (in this case represented by the increase in the depth-of-focus) reduces the LAG of accommodation, and this can be one of the main factors contributing to this [35]. Furthermore, the limitations of the methods used for measuring the accommodative response, which were subjective methods, Nott and MEM, should also be noted. These methods have been demonstrated to have a limited repeatability, as demonstrated by Antona et al. [36]. This could have introduced some level of variability which is inherent to the measurement procedure, although the same experienced examiner obtained all measurements. Considering this, future studies should confirm this reduction in the accommodative LAG with objective methods and if it is maintained in the long term.

Concerning the impact of myopia control CLs on binocularity, only two previous studies have evaluated this issue, reporting a slight increase in exophoria at near without alteration of stereopsis $[19,30]$. These results are consistent with those obtained in the current series. However, to our knowledge, no study has investigated the impact of myopia control CL wear on fusional vergences. In our study, a trend to improvement was observed in positive FV at near, suggesting a potentially greater ability to converge with the CL. This increase could be due to the vergence-accommodation synergy and consequently could be associated with the decrease in the accommodative LAG. This should be investigated further in future studies. Concerning the minimal variations of the measurements obtained with the cover test, it may be associated with the inherent variability of the measurement of the phoria, especially in this reduced sample [37].

Besides VA, accommodation and binocular evaluation, an analysis of the impact of the wearing of the EDOF CL evaluated on ocular aberrations and perception of photic phenomena was also performed. To date, few studies have evaluated changes in ocular aberrations with CLs for myopia control [17,20,38,39]. In our sample, a significant increase was found with the CL wear in HOA RMS, primary coma RMS, primary spherical aberration Zernike term and secondary astigmatism RMS for both 3 and $5 \mathrm{~mm}$ pupils, but always reaching values within the range of variability of ocular aberrations defined for the healthy population using the same multi-diagnostic platform [40]. By increasing the pupil diameter, a trend to a change to negative primary spherical aberration was observed together with changes of small magnitude although statistically significant for the rest of the 
aberrometric coefficients, suggesting that the EDOF design allows a controlled induction of HOAs leading to a minimally pupil dependent depth-of-focus range. Bakaraju et al. [23] in a simulation study computing the through focus retinal image quality demonstrated that the EDOF CL design used in the current series deliberately induced multiple higher-order aberrations making the optical quality of the $\mathrm{CL}+$ eye system less susceptible to variations in the pupil, inherent ocular aberrations and lens decentration.

The increase in ocular aberrations with the CL evaluated could be related to the initial reduction in visual acuity observed in the current series. Yazar et al. [41] found that more reduced visual acuity was present in healthy subjects with more levels of comalike aberrations. Besides the impact on visual acuity, the increase in aberrations can also promote the perception of photic phenomena, such as glare, halos and starburst. For this reason, a self-developed questionnaire was used to ask patients about the frequency and level of bothersomeness of these three photic phenomena. A trend to an increase in the perception of photic phenomena with the CL wear was observed but in most cases occasionally and inducing mild bothersomeness. Kang et al. [42] and Huang et al. [43] used a validated questionnaire of quality of vision to analyze the impact of off-label multifocal CL fitting for myopia control, reporting the presence of a certain level of blurred vision, visual fluctuation, focus difficulty and photic symptoms. Specifically, Huang et al. [43] reported a decrease in these photic symptoms after one month of CL use, except for halos. Our study showed a low incidence of glare and halos before and after CL wear, with no patient reporting the perception of moderate or severe glare or halos. These data are consistent with those obtained by Sha et al. [34], who also found a low incidence of halos and glare with an EDOF CL. Almost half of the sample of patients reported the perception of starbursts before fitting (46.7\%), and after 30 days of CL wear $(46.2 \%)$, most of them referred to this photic phenomenon as mild or minimally bothersome.

Other changes with the EDOF CL were also investigated, such as pupillary and anatomical modifications. In the present study, a significant decrease in pupil size measured under photopic conditions was detected, although the change was small in magnitude $(0.19 \mathrm{~mm})$ and of potentially low clinical relevance. This may be due to the contribution of several factors, such as the inherent variability of the measurement procedure, changes in the emotional or mental status or even the variability associated with the physiological pupillary hyppus [44]. Changes in visuocortical activity are not systematically related to pupil size modifications [45]. Therefore, it is difficult to confirm if this minimal pupillary change is associated with the EDOF CL wear, with more studies being necessary. Concerning keratometry, no significant changes were detected with the CL wear. The clinical trials carried out by Pauné et al. [16] and García-del-Valle et al. [21] evaluated the morphological changes of the cornea after prolonged use of myopia control CLs, without obtaining variations in either keratometry or pachymetry. These results are consistent with those obtained in our study. However, although changes in CCT did not reach statistical significance, a slight tendency towards an increase in this parameter was found, which could be due to the typical corneal oedema associated with hydrophilic CL wearing [46]. However, none of the subjects presented ocular complications of a pathological nature. Biometrically, no variations in AXL were observed, as might be expected due to the short duration of the study. On the other hand, a small in magnitude but statistically significant reduction in ACD was observed after one month of use of the EDOF CL. A similar finding has already been reported by Pauné et al. [16]. This may be attributed to several factors, including the accuracy of the measurement procedure, or the presence of uncontrolled accommodative responses during the measurement (some level of instrumental myopia) leading to small changes in the crystalline lens thickness [47] and consequently in ACD. More studies are needed to confirm the relevance of this finding and its real relationship with the effect itself of the EDOF CL.

This pilot study has the main limitation of the low sample size, with two dropped out cases. However, it was a pilot study to detect potential changes to investigate in future larger sample sizes. In any case, the statistical power associated with most of compara- 
tive analyses was enough to detect the presence of significant changes. Furthermore, the design of the study could be considered as another relevant limitation as a control group was not included. This should be applied in future studies. Despite these limitations, all measurements were conducted by an experienced examiner following the same clinical protocol used in a previous study evaluating another type of myopia control contact lens [21]. In addition, the validity and consistency of corneal topographic, ocular aberrometric, pupillometric and anatomical measurements obtained in the current study with the multidiagnostic platform used were demonstrated and reported in previous studies conducted by our research group [40,48-50]. Finally, there are some limitations in the measurement of visual acuity that must be acknowledged. The visual acuity was measured under mesopic conditions, and considering the aberrometric profile of the CL, better visual acuity would have been expected under photopic conditions, something that should be confirmed in future studies. Furthermore, non-randomized optotypes and psychometric methods were used for the measurement of the visual acuity, a factor that might have introduced some variability in the measures.

\section{Conclusions}

In conclusion, the EDOF CL Mylo may provide a satisfactory visual acuity and quality after one month of use, combined with a controlled increase in several HOAs and a trend to reduction in the accommodative LAG. Other changes found in the current series such as the reduction in pupil size measured under photopic conditions and ACD should be investigated further to confirm its real relationship with the effect of the EOF CL. More research increasing the sample size and including a control group is needed to investigate how all these changes are related and how they allow the control of eyeball elongation.

Author Contributions: Conceptualization, G.C. and D.P.P.; methodology, G.C. and D.P.P.; formal analysis, G.C. and D.P.P.; investigation, G.C. and D.P.P.; resources, D.P.P.; data curation, G.C.; writingoriginal draft preparation, G.C.; writing-review and editing, D.P.P.; visualization, G.C. and D.P.P.; supervision, D.P.P.; project administration, D.P.P.; funding acquisition, D.P.P. All authors have read and agreed to the published version of the manuscript.

Funding: The author David P. Piñero has received funding from the Ministry of Economy, Industry and Competitiveness of Spain within the program Ramón y Cajal, RYC-2016-20471.

Institutional Review Board Statement: The study was conducted according to the guidelines of the Declaration of Helsinki, and approved by the Ethics Committee for Medical Research of the Health Department of Alicante (General Hospital, Alicante, Spain) (CEIm 2020-048, ISABIAL 200045).

Informed Consent Statement: Informed consent was obtained from parents of all children involved in the study.

Data Availability Statement: Data available on request due to privacy/ethical restrictions.

Conflicts of Interest: The authors declare no conflict of interest.

\section{References}

1. Flitcroft, D.I.; He, M.; Jonas, J.B.; Jong, M.; Naidoo, K.; Ohno-Matsui, K.; Rahi, J.; Resnikoff, S.; Vitale, S.; Yannuzzi, L. IMIDefining and Classifying Myopia: A Proposed Set of Standards for Clinical and Epidemiologic Studies. Investig. Opthalmol. Vis. Sci. 2019, 60, 20-30. [CrossRef]

2. Haarman, A.E.G.; Enthoven, C.A.; Tideman, J.W.L.; Tedja, M.S.; Verhoeven, V.J.M.; Klaver, C.C.W. The Complications of Myopia: A Review and Meta-Analysis. Investig. Opthalmol. Vis. Sci. 2020, 61, 49. [CrossRef]

3. Wu, P.-C.; Huang, H.-M.; Yu, H.-J.; Fang, P.-C.; Chen, C.-T. Epidemiology of Myopia. Asia-Pac. J. Ophthalmol. $2016,5,386-393$. [CrossRef]

4. Holden, B.A.; Fricke, T.R.; Wilson, D.A.; Jong, M.; Naidoo, K.S.; Sankaridurg, P.; Wong, T.Y.; Naduvilath, T.; Resnikoff, S. Global Prevalence of Myopia and High Myopia and Temporal Trends from 2000 through 2050. Ophthalmology 2016, 123, 1036-1042. [CrossRef] [PubMed]

5. Cooper, J.; Tkatchenko, A.V. A Review of Current Concepts of the Etiology and Treatment of Myopia. Eye Contact Lens. Sci. Clin. Pr. 2018, 44, 231-247. [CrossRef] [PubMed] 
6. Wildsoet, C.F.; Chia, A.; Cho, P.; Guggenheim, J.A.; Polling, J.R.; Read, S.; Sankaridurg, P.; Saw, S.M.; Trier, K.; Walline, J.J.; et al. IMI-Interventions Myopia Institute: Interventions for controlling myopia onset and progression report. Investig. Ophthalmol. Vis. Sci. 2019, 60, 106-131. [CrossRef]

7. Prousali, E.; Haidich, A.-B.; Fontalis, A.; Ziakas, N.; Brazitikos, P.; Mataftsi, A. Efficacy and safety of interventions to control myopia progression in children: An overview of systematic reviews and meta-analyses. BMC Ophthalmol. 2019, 19, 106. [CrossRef]

8. Huang, J.; Wen, D.; Wang, Q.; McAlinden, C.; Flitcroft, I.; Chen, H.; Saw, S.M.; Chen, H.; Bao, F.; Zhao, Y.; et al. Efficacy comparison of 16 interventions for myopia control in children: A network meta-analysis. Ophthalmology 2016, 123, 97-708. [CrossRef]

9. Benavente-Perez, A.; Nour, A.; Troilo, D. The effect of simultaneous negative and positive defocus on eye growth and development of refractive state in marmosets. Investig. Ophthalmol. Vis. Sci. 2012, 53, 6479-6487. [CrossRef] [PubMed]

10. Smith, E.L., III; Hung, L.F.; Huang, J. Relative peripheral hyperopic defocus alters central refractive development in infant monkeys. Vis. Res. 2009, 49, 2386-2392. [CrossRef]

11. Smith, E.L.; Kee, C.-S.; Ramamirtham, R.; Qiao-Grider, Y.; Hung, L.-F. Peripheral Vision Can Influence Eye Growth and Refractive Development in Infant Monkeys. Investig. Opthalmol. Vis. Sci. 2005, 46, 3965-3972. [CrossRef]

12. Thibos, L.N.; Bradley, A.; Liu, T.; López-Gil, N. Spherical Aberration and the Sign of Defocus. Optom. Vis. Sci. 2013, 90, 1284-1291. [CrossRef]

13. Sah, R.P.; Ramasubramanian, V.; Reed, O.; Meyer, D.; Bradley, A.; Kollbaum, P.S. Accommodative Behavior, Hyperopic Defocus, and Retinal Image Quality in Children Viewing Electronic Displays. Optom. Vis. Sci. 2020, 97, 628-640. [CrossRef] [PubMed]

14. Walline, J.J.; Giannoni, A.G.; Sinnott, L.T.; Chandler, M.A.; Huang, J.; Mutti, D.O.; Jones-Jordan, L.A.; Berntsen, D. A Randomized Trial of Soft Multifocal Contact Lenses for Myopia Control: Baseline Data and Methods. Optom. Vis. Sci. 2017, 94, 856-866. [CrossRef] [PubMed]

15. Aller, T.A.; Liu, M.; Wildsoet, C.F. Myopia control with bifocal contact lenses: A randomized clinical trial. Optom. Vis. Sci. 2016, 93, 344-352. [CrossRef] [PubMed]

16. Pauné, J.; Morales, H.; Armengol, J.; Quevedo, L.; Faria-Ribeiro, M.; González-Méijome, J.M. Myopia Control with a Novel Peripheral Gradient Soft Lens and Orthokeratology: A 2-Year Clinical Trial. BioMed Res. Int. 2015, 2015, 507572. [CrossRef] [PubMed]

17. Pauné, J.; Thivent, S.; Armengol, J.; Quevedo, L.; Faria-Ribeiro, M.; González-Méijome, J.M. Changes in Peripheral Refraction, Higher-Order Aberrations, and Accommodative Lag with a Radial Refractive Gradient Contact Lens in Young Myopes. Eye Contact Lens Sci. Clin. Pract. 2016, 42, 380-387. [CrossRef]

18. Ruiz-Pomeda, A.; Pérez-Sánchez, B.; Valls, I.; Garrido, F.L.P.; Gutierrez, R.; Villa-Collar, C. MiSight Assessment Study Spain (MASS). A 2-year randomized clinical trial. Graefe Arch. Clin. Exp. Ophthalmol. 2018, 256, 1011-1021. [CrossRef]

19. Ruiz-Pomeda, A.; Pérez-Sánchez, B.; Cañadas, P.; Prieto-Garrido, F.L.; Gutiérrez-Ortega, R.; Villa-Collar, C. Binocular and accommodative function in the controlled randomized clinical trial MiSight ${ }^{\circledR}$ Assessment Study Spain (MASS). Graefe Arch. Clin. Exp. Ophthalmol. 2018, 257, 207-215. [CrossRef] [PubMed]

20. Lopes-Ferreira, D.; Ruiz-Pomeda, A.; Peréz-Sanchéz, B.; Queirós, A.; Villa-Collar, C. Ocular and corneal aberrations changes in controlled randomized clinical trial MiSight ${ }^{\circledR}$ Assessment Study Spain (MASS). BMC Ophthalmol. 2021, 21, 1-7. [CrossRef]

21. Garcia-del Valle, A.M.; Blázquez, V.; Gros-Otero, J.; Infante, M.; Culebras, A.; Verdejo, A.; Sebastián, J.; García, M.; Bueno, S.; Piñero, D.P. Efficacy and safety of a soft contact lens to control myopia progression. Clin. Exp. Optom. 2021, 104, 14-21. [CrossRef]

22. Przekoracka, K.; Michalak, K.; Olszewski, J.; Zeri, F.; Michalski, A.; Paluch, J.; Przekoracka-Krawczyk, A. Contrast sensitivity and visual acuity in subjects wearing multifocal contact lenses with high additions designed for myopia progression control. Contact Lens. Anterior. Eye 2020, 43, 33-39. [CrossRef] [PubMed]

23. Bakaraju, R.C.; Ehrmann, K.; Ho, A. Extended depth of focus contact lenses vs. two commercial multifocals: Part 1. Optical performance evaluation via computed through-focus retinal image quality metrics. J. Optom. 2018, 11, 10-20. [CrossRef] [PubMed]

24. Piñero, D.P. Efecto a nivel óptico de la lente de contacto de control de miopía Mylo. Gaceta Optom. Ópt. Oftálmica 2019, 553, 90-92.

25. Sankaridurg, P.; Bakaraju, R.C.; Naduvilath, T.; Chen, X.; Weng, R.; Tilia, D.; Xu, P.; Li, W.; Conrad, F.; Smith, E.L.; et al. Myopia control with novel central and peripheral plus contact lenses and extended depth of focus contact lenses: 2 year results from a randomised clinical trial. Ophthalmic Physiol. Opt. 2019, 39, 294-307. [CrossRef] [PubMed]

26. Nguyen, A.T.; Wayne, J.L.; Ravikumar, A.; Manny, R.E.; Anderson, H.A. Accommodative accuracy by retinoscopy versus autorefraction spherical equivalent or horizontal meridian power. Clin. Exp. Optom. 2018, 101, 778-785. [CrossRef] [PubMed]

27. Dwyer, P.S. Clinical criteria for vergence accommodation dysfunction. Clin. Exp. Optom. 1991, 74, 112-119. [CrossRef]

28. Bakaraju, R.C.; Tilia, D.; Sha, J. Extended depth of focus contact lenses vs. two commercial multifocals: Part 2. Visual performance after 1 week of lens wear. J. Optom. 2018, 11, 21-32. [CrossRef] [PubMed]

29. Dupont, W.D.; Plummer, W.D. Power and sample size calculations: A review and computer program. Control. Clin. Trials 1990, 11, 116-128. [CrossRef]

30. Tilia, D.; Sha, J.; Thomas, V.; Bakaraju, R.C. Vision Performance and Accommodative/Binocular Function in Children Wearing Prototype Extended Depth-of-Focus Contact Lenses. Eye Contact Lens Sci. Clin. Pract. 2019, 45, 260-270. [CrossRef]

31. Chamberlain, P.; Peixoto-De-Matos, S.C.; Logan, N.S.; Ngo, C.; Jones, D.; Young, G. A 3-year Randomized Clinical Trial of MiSight Lenses for Myopia Control. Optom. Vis. Sci. 2019, 96, 556-567. [CrossRef]

32. Kollbaum, P.S.; Jansen, M.E.; Tan, J.; Meyer, D.M.; Rickert, M.E. Vision Performance with a Contact Lens Designed to Slow Myopia Progression. Optom. Vis. Sci. 2013, 90, 205-214. [CrossRef] 
33. Rosa, A.M.; Miranda, Â.C.; Patrício, M.M.; McAlinden, C.; Silva, F.L.; Castelo-Branco, M.; Murta, J.N. Functional magnetic resonance imaging to assess neuroadaptation to multifocal intraocular lenses. J. Cataract. Refract. Surg. 2017, 43, 1287-1296. [CrossRef] [PubMed]

34. Sha, J.; Tilia, D.; Diec, J.; Fedtke, C.; Yeotikar, N.; Jong, M.; Thomas, V.; Bakaraju, R.C. Visual performance of myopia control soft contact lenses in non-presbyopic myopes. Clin. Optom. 2018, 10, 75-86. [CrossRef]

35. Antona, B.; Sanchez, I.; Barrio, A.; Barra, F.; Gonzalez, E. Intra-examiner repeatability and agreement in accommodative response measurements. Ophthalmic Physiol. Opt. 2009, 29, 606-614. [CrossRef]

36. Schilling, T.; Ohlendorf, A.; Varnas, S.R.; Wahl, S. Peripheral Design of Progressive Addition Lenses and the Lag of Accommodation in Myopes. Investig. Opthalmol. Vis. Sci. 2017, 58, 3319. [CrossRef] [PubMed]

37. Anstice, N.S.; Davidson, B.; Field, B.; Mathan, J.; Collins, A.V.; Black, J.M. The repeatability and reproducibility of four techniques for measuring horizontal heterophoria: Implications for clinical practice. J. Optom. 2020, 14, 275-281. [CrossRef]

38. Hughes, R.P.; Vincent, S.; Read, S.; Collins, M. Higher order aberrations, refractive error development and myopia control: A review. Clin. Exp. Optom. 2020, 103, 68-85. [CrossRef]

39. Fedtke, C.; Ehrmann, K.; Thomas, V.; Bakaraju, R.C. Peripheral Refraction and Aberration Profiles with Multifocal Lenses. Optom. Vis. Sci. 2017, 94, 876-885. [CrossRef] [PubMed]

40. Piñero, D.P.; López-Navarro, A.; Cabezos, I.; de Fez, D.; Caballero, M.T.; Camps, V.J. Intrasession repeatability of refractive and ocular aberrometric measurements obtained using a multidiagnostic device in healthy eyes. Clin. Optom. 2017, 9, 91-96. [CrossRef] [PubMed]

41. Yazar, S.; Hewitt, A.; Forward, H.; McKnight, C.M.; Tan, A.; Mountain, J.A.; Mackey, D.A. Comparison of monochromatic aberrations in young adults with different visual acuity and refractive errors. J. Cataract. Refract. Surg. 2014, 40, 441-449. [CrossRef]

42. Kang, P.; McAlinden, C.; Wildsoet, C.F. Effects of multifocal soft contact lenses used to slow myopia progression on quality of vision in young adults. Acta Ophthalmol. 2016, 95, e43-e53. [CrossRef]

43. Huang, X.; Wang, F.; Lin, Z.; He, Y.; Wen, S.; Zhou, L.; Lu, F.; Jiang, J. Visual quality of juvenile myopes wearing multifocal soft contact lenses. Eye Vis. 2020, 7, 1-8. [CrossRef]

44. Aminihajibashi, S.; Hagen, T.; Foldal, M.D.; Laeng, B.; Espeseth, T. Individual differences in resting-state pupil size: Evidence for association between working memory capacity and pupil size variability. Int. J. Psychophysiol. 2019, 140, 1-7. [CrossRef]

45. Thigpen, N.N.; Bradley, M.M.; Keil, A. Assessing the relationship between pupil diameter and visuocortical activity. J. Vis. 2018, 18, 7. [CrossRef]

46. Nourouzi, H.; Rajavi, J.; Okhovatpour, M.A. Time to Resolution of Corneal Edema after Long-Term Contact Lens Wear. Am. J. Ophthalmol. 2006, 142, 671-673. [CrossRef] [PubMed]

47. Drexler, W.; Baumgartner, A.; Findl, O.; Hitzenberger, C.K.; Fercher, A.F. Biometric investigation of changes in the anterior eye segment during accommodation. Vis. Res. 1997, 37, 2789-2800. [CrossRef]

48. Gordon-Shaag, A.; Piñero, D.P.; Kahloun, C.; Markov, D.; Parnes, T.; Gantz, L.; Shneor, E. Validation of refraction and anterior segment parameters by a new multi-diagnostic platform (VX120). J. Optom. 2018, 11, 242-251. [CrossRef] [PubMed]

49. Piñero, D.P.; Cabezos, I.; López-Navarro, A.; De Fez, D.; Caballero, M.T.; Camps, V.J. Intrasession repeatability of ocular anatomical measurements obtained with a multidiagnostic device in healthy eyes. BMC Ophthalmol. 2017, 17, 193. [CrossRef] [PubMed]

50. Piñero, D.P.; López-Navarro, A.; Cabezos, I.; De Fez, D.; Caballero, M.T.; Camps, V.J. Corneal Topographic and Aberrometric Measurements Obtained with a Multidiagnostic Device in Healthy Eyes: Intrasession Repeatability. J. Ophthalmol. 2017, 2017, 2149145. [CrossRef] 